\title{
Rivers and flooded areas identified by medium-resolution remote sensing improve risk prediction of the highly pathogenic avian influenza $\mathrm{H} 5 \mathrm{~N} 1$ in Thailand
}

\author{
Weerapong Thanapongtharm ${ }^{1,2}$, Thomas P. Van Boeckel ${ }^{2,3}$, Chandrashekhar Biradar ${ }^{5}$, \\ Xiangming $\mathrm{XiaO}^{4}$, Marius Gilbert ${ }^{2,3}$ \\ ${ }^{1}$ Burean of Disease Control and Veterinary Services, Department of Livestock Development, Bangkok, \\ Thailand; ${ }^{2}$ Biological Control and Spatial Ecology, Université Libre de Bruxelles, Brussels, Belgium; ${ }^{3}$ Fonds \\ National de la Recherche Scientifique, Brussels, Belgium; ${ }^{4}$ Department of Microbiology and Plant Biology, \\ Center for Spatial Analysis, University of Oklahoma, Norman, USA; ${ }^{5}$ International Center for Agricultural \\ Research in Dry Areas, Amman, Jordan
}

\begin{abstract}
Thailand experienced several epidemic waves of the highly pathogenic avian influenza (HPAI) H5N1 between 2004 and 2005. This study investigated the role of water in the landscape, which has not been previously assessed because of a lack of high-resolution information on the distribution of flooded land at the time of the epidemic. Nine Landsat 7Enhanced Thematic Mapper Plus scenes covering 174,610 km² were processed using k-means unsupervised classification to map the distribution of flooded areas as well as permanent lakes and reservoirs at the time of the main epidemic HPAI H5N1 wave of October 2004. These variables, together with other factors previously identified as significantly associated with risk, were entered into an autologistic regression model in order to quantify the gain in risk explanation over previously published models. We found that, in addition to other factors previously identified as associated with risk, the proportion of land covered by flooding along with expansion of rivers and streams, derived from an existing, sub-district level (administrative level no. 3) geographical information system database, was a highly significant risk factor in this 2004 HPAI epidemic. These results suggest that water-borne transmission could have partly contributed to the spread of HPAI H5N1 during the epidemic. Future work stemming from these results should involve studies where the actual distribution of small canals, rivers, ponds, rice paddy fields and farms are mapped and tested against farm-level data with respect to HPAI H5N1.
\end{abstract}

Keywords: highly pathogenic avian influenza, flooding, remote sensing, Landsat, Thailand.

\section{Introduction}

Highly pathogenic avian influenza (HPAI) H5N1 first appeared in Thailand in early 2004 and the country faced several epidemics in 2004 and 2005, outbreaks of which the World Organization for Animal Health (OIE) was duly notified. In the following years, the disease reoccurred sporadically with four, three and four outbreaks in 2006, 2007 and 2008, respectively (OIE, 2011). In October 2004, Thailand's Department of Livestock Development implemented a national-wide, active surveillance system, termed the "x-ray surveys", in order to produce a comprehensive view of the epidemiological situation in the field and mount a response

Corresponding author:

Weerapong Thanapongtharm

Department of Livestock Development

Bureau of Disease Control and Veterinary Services

69/1, Phayathai road, Ratchatewi, Bangkok 10400, Thailand

Tel. +662 653 4444; Fax +662 6534921

E-mail: weeraden@yahoo.com to the epidemic for the immediate future. A longer-term control strategy was also planned. The survey, carried out by 100,000 trained inspectors, provided an unprecedented dataset of HPAI H5N1 including disease status and poultry census georeferenced at the village level (Tiensin et al., 2005, 2007). Thanks to this detailed dataset, the spatial epidemiology of HPAI H5N1 in Thailand could be analysed in a number of studies involving descriptive mapping tools (Tiensin et al., 2005, 2007), statistical and geo-statistical approaches (Gilbert et al., 2006; Tiensin et al., 2009; Paul et al., 2010; Souris et al., 2010; Walker et al., 2012) or mathematical modelling (Marquetoux et al., 2012). Those studies helped characterise the main spatio-temporal patterns of $\mathrm{H} 5 \mathrm{~N} 1$ outbreaks during the epidemics and also substantially contribute to identifying the risk factors associated with HPAI $\mathrm{H} 5 \mathrm{~N} 1$ with implications at large spatial scales such as, for example, the distribution of free-grazing ducks and rice production areas in Thailand and beyond (Gilbert et al., 2006, 2007, 2008). However, this factor seems to have had a lower effect on risk in countries where duck farming is less intensive 
than Thailand, such as Indonesia (Loth et al., 2011) or Bangladesh (Loth et al., 2010; Gilbert et al., 2011; Ahmed et al., 2012).

In Thailand, the main risk factors found to be associated with HPAI H5N1 are free-grazing ducks, native chickens and the proportion of cocks (Gilbert et al., 2006; Tiensin et al., 2009; Paul et al., 2010). However, Tiensin et al. (2009) also found native chickens to be negatively associated with $\mathrm{H} 5 \mathrm{~N} 1$ risk. In addition, several other risk factors, not related to the density of potential hosts, were identified at the sub-district level (administrative level no. 3), e.g. low elevation, high human population density, high crop intensity, presence of roads and presence of slaughterhouses. At the farm level, the risk factors were purchase of poultry from other farms, presence of ponds or canals near farmhouses and use of disinfectants to clean poultry areas. A review of factors identified in Thailand and in other countries has been carried out by Gilbert and Pfeiffer (2012).

Water has long been suspected to play an important role in the persistence and spread of HPAI H5N1. Water-borne transmission is an important element of transmission of low pathogenic avian influenza in wild birds, while other avian influenza viruses, H5N1 Highly pathogenic avian influenza virus (HPAIV) in particular, have been demonstrated to persist in water under various conditions (Brown et al., 2009; Domanska-Blicharz et al., 2010). Moreover, the HPAI $\mathrm{H} 5 \mathrm{~N} 1$ virus has been shown to survive for 3 days in water obtained from rice fields where ducks infected with HPAI H5N had been raised (Songserm et al., 2005). Surprisingly, however, few studies include a measure of the abundance of water in the landscape as a risk factor for HPAI H5N1, and the few studies that do report such an effect were not carried out in Thailand (Pfeiffer et al., 2007; Adhikari et al., 2009). Instead, previous studies in Thailand found HPAI H5N1 outbreaks to be strongly associated with lowland and areas producing multiple crops per year, though they provide no strong causal mechanism to explain these relationships. However, high crop intensity can only be carried out in irrigated/inundated areas, and this type of landscape in Thailand happens to exist in the Chao Phraya plain, where also most influenza outbreaks occurred. Therefore, these two factors may in fact be confounders of densely irrigated areas where HPAI H5N1 transmission would be mediated by contaminated water at the landscape level. In addition, strong rains occasionally cause floods that unexpectedly expand the inundated lands and further promote water-borne transmission.
In this study, we aimed to replicate some of the previous statistical modelling of HPAI H5N1 in Thailand by testing water-related variables in addition to the variables previously found to be associated with HPAI H5N1 (Gilbert et al., 2006). The availability of reliable data on water streams and irrigation was a limiting factor in previous studies. However, freely available medium-resolution, remote sensing has the potential to compensate for this lack of field-related data by providing maps of the water situation at various times, something that could considerably help refining the spatial prediction of HPAI H5N1 risk (Tran et al., 2010). Armed with this type of data, quantified from existing geographical information system (GIS) investigations, we set out to test the effect of the density of rivers and streams (the total length of rivers and streams per sub-district divided by their area) and the proportion of land covered by water during the second epidemic wave in October 2004 in each sub-district.

\section{Materials and methods}

\section{Datasets used}

In order to make the results comparable to previous studies, the HPAI H5N1 outbreak dataset used in this study was the same as the one analysed in Gilbert et al. (2008) with one notable difference. Instead of pooling poultry categories, which was necessary in Gilbert et al. (2008) to allow comparison with data from Vietnam, we used the individual poultry categories that were already analysed by Gilbert et al. (2006) and Tiensin et al. (2009). These data included the number of native chickens, free-grazing ducks, meat-and-layer chickens, meat-and-layer ducks and the proportion of cocks. The analysis also included human population density and crop intensity as previously described (Gilbert et al., 2008).

\section{Study area and remote sensing}

The study area cantered on the central Chao Phraya plain which covers an area of $174,610 \mathrm{~km}^{2}$ of lower north, central and some north-eastern parts of Thailand. Nine scenes of the Landsat 7-Enhanced Thematic Mapper Plus (Landsat 7-ETM+) were required to cover $95 \%$ of the second-wave outbreaks of the 2004-2005 period. Landsat 7-ETM+ sensors have six optical multi-spectral bands at $30-\mathrm{m}$ spatial resolution and one panchromatic band at $15-\mathrm{m}$ spatial resolution and a 16-day revisit cycle. We searched the Landsat image archive at the United States Geological 
Survey EROS Data Center (http://www.usgs.gov) and downloaded good quality images with little or low cloud cover from May 2004 to April 2005. Landsat 7 was launched on April 15, 1999 but the Scan Line Corrector (SLC) in the ETM instrument failed on May 31, 2003, which results in stripes of data missing. We used the multi-scene gap-filling method to fill the SLC off gaps (Scaramuzza et al., 2004). Gap filled images were stacked and mosaiced for the image classification.

The k-means unsupervised classification method (Tou and Gonzalez, 1974) was used for land cover mapping. The main criteria for choosing of the $\mathrm{k}$ means algorithm was to minimise the within-cluster variability as we intend to identify flooded areas with varying levels of surface water reflectivity due to clarity, turbidity and suspended materials in the flooding water. A common use for the k-means approach is when landscape patterns and environmental characteristics are complex, and when it is not feasible to predefine classes in an image. The method calculates initial class means evenly distributed in the data space and then iteratively clusters the pixels into the nearest class using a minimum distance technique. Each iteration recalculates class means and reclassifies pixels with respect to the new means. All pixels are classified to the nearest class unless a standard deviation or distance threshold is specified, in which case some pixels may be unclassified if they do not meet the selected criteria. This process continues until the number of pixels in each class changes by less than the selected pixel change threshold or the maximum number of iterations is reached. Ten classes were used here in order to seek the optimal separation of water classes from other types of land cover. The Exelis VIS ENVI (formerly ITT ENVI) image processing software package was used to classify the satellite images as explained above (Exelis VIS, 2010).

Visible composite image and the spectral profile allowing examination of the spectral characteristics of the classified cluster were examined for class identification and naming. Only the classes composed of water bodies (lakes, rivers, streams and floods) were selected and combined in one class to be used for the statistical models. We post-evaluated the accuracy of the water class with additional ground truth data and high-resolution data from Google Earth images for accuracy. At $89 \%$, this value was found acceptable and sufficient for the analysis.

Because lakes, rivers, streams and floods were difficult to accurately separate in the satellite image classification, a GIS dataset of water bodies composed of lake, rivers and streams from the Transport
Fundamental Geographic Dataset (FGDS, Ministry of Transport) were included in this study. Three variables were summarised at the sub-district level: the proportion of land covered by water quantified from the Landsat image classification (that could be lake, rivers, streams and flooded lands), the proportion of land covered by lakes estimated from the GIS database, and the density of rivers and streams estimated from the GIS database.

\section{Analysis}

In order to remain consistent with the previously published models by Gilbert et al. (2006, 2008), we adopted a similar, autologistic regression analytical method to relate the presence or absence of HPAI $\mathrm{H} 5 \mathrm{~N} 1$ in a sub-district to all predictors (Gilbert et al., 2008). In the autologistic regressions, an autoregressive term accounted for neighbouring observations weighted by their distance was included as covariate to the logistic regression to account for spatial autocorrelation (Augustin et al., 1996) As in those previous studies, the analysis was bootstrapped by randomly selecting three negative sub-districts for each positive at each bootstrap in order to avoid making the positive/negative ratio too unbalanced. Because classification of satellite imagery was only carried out for the central Chao Phraya Plain, the water-related variable was not available in the rest of the country (see Fig. 1). In order not to restrict our analysis to the central plain, which would have led to loss of other outbreaks and sub-districts in the analysis, we replaced the missing values at each bootstrap by values sampled from a normal distribution with the same mean and standard deviation as those observed in sub-districts where the values where available. Finally, as the remote sensing data only covered the period of the second part of the 2004-2005 epidemics, these variables were only tested against the HPAI H5N1 outbreaks recorded during the period from October 1, 2004 to April 1, 2005.

We constructed five different models, the first two of which were built to match our previously published work, i.e. they included poultry variables, human population density and crop intensity. These first two models corresponded to each study periods: July 3, 2004 - September 30, 2004 (period I) and October 1, 2004 - April 30, 2005 (period II). The third model included the same variables and covered the same period as the second (period II) but with the inclusion of the following water-related variables: proportion of land covered by water (from Landsat), the proportion 
(a)

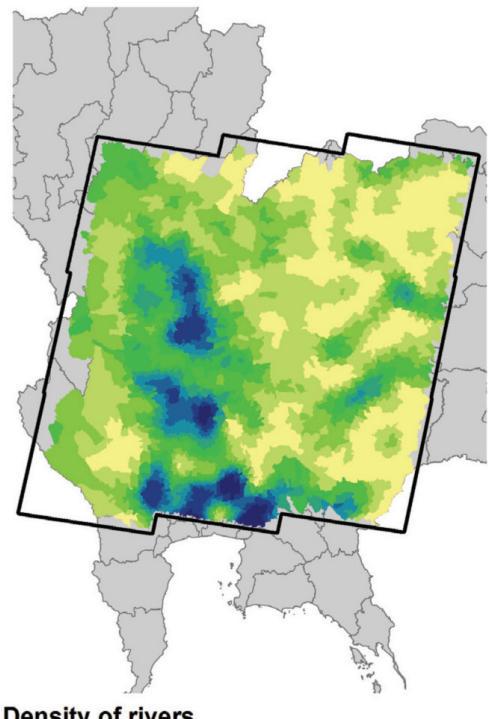

Density of rivers

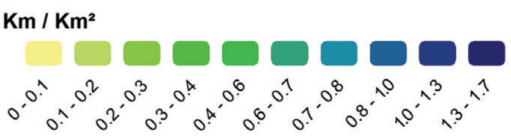

(b)

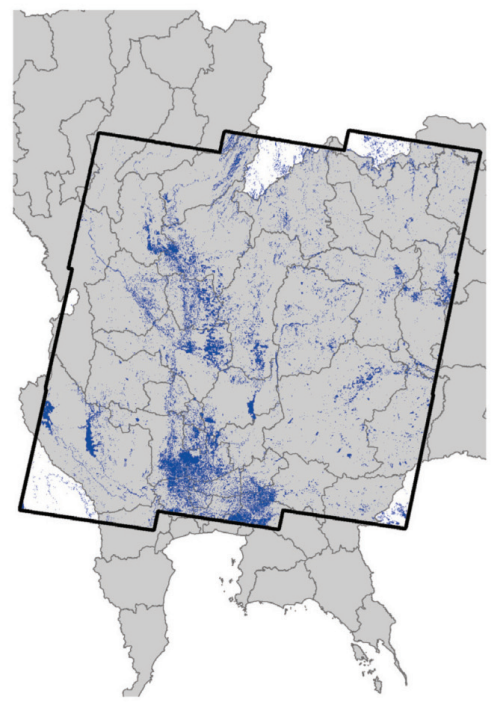

(c)

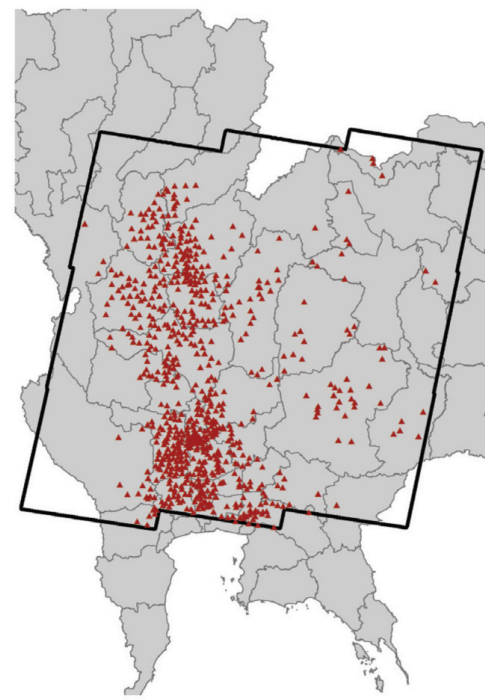

HPAI H5N1

$\triangle$ Outbreak

Flooded

Fig. 1. The waterbody situation during the main epidemic wave of HPAI H5N1 in Thailand in October 2004. (a) Density of rivers and streams derived from hydrographic maps; (b) distribution of areas classified as water bodies; (c) outbreak distribution.

of land covered by lake (from GIS data) and the density of rivers and streams (from GIS data). The goal of building this third model was to quantify the improvement of the previous model by the inclusion of waterrelated variables. In addition, we also aimed to quantify if water-related variables affected the distribution of HPAI H5N1 outbreaks in chicken and ducks differently. We then built two additional models for period II: one where the dependent variable was the presence or absence of HPAI H5N1 in a chicken farm, and another where the dependent variable was the presence or absence of HPAI H5N1 in a duck farm.

\section{Results}

Table 1 summarises the significance and sign of the predictors in the different models. In the two default models (1 and 2; Table 1), corresponding to previous publications (Gilbert et al., 2006) using the same modelling framework, the main predictors during the first

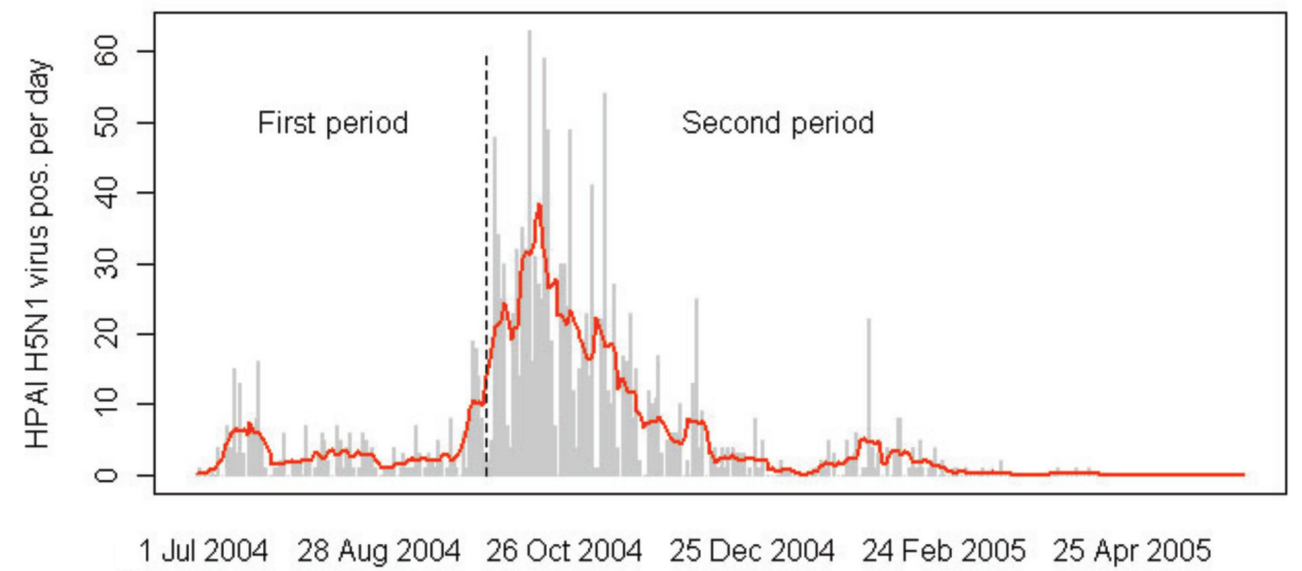

Fig. 2. HPAI H5N1 virus loads during the epidemic of July 1, 2004 - April 30, 2005. The grey bars indicate the daily number of HPAI H5N1 oubtreaks with the red curve showing the weekly moving window average. The dotted, vertical line marks the separation between the two study periods corresponding to the onset of the active surveillance survey. 
Table 1. Summary results of the autologistic regression models.

\begin{tabular}{|c|c|c|c|c|c|}
\hline Model & 1 & 2 & 3 & 4 & 5 \\
\hline Outbreaks & All & All & All & In chickens & In ducks \\
\hline Water predictors & No & No & Yes & Yes & Yes \\
\hline Application period & I & II & II & II & II \\
\hline \multicolumn{6}{|l|}{ Variable } \\
\hline Broiler and layer chicken & n.s. & n.s. & n.s. & n.s. & n.s. \\
\hline Native chickens & +++ & n.s. & n.s. & n.s. & - \\
\hline Meat-and-layer duck & n.s. & n.s. & n.s. & n.s. & +++ \\
\hline Free-grazing duck & + & +++ & +++ & +++ & +++ \\
\hline Cock & +++ & +++ & +++ & +++ & +++ \\
\hline Human population & + & n.s. & n.s. & n.s. & n.s. \\
\hline Mean crop intensity & ++ & +++ & +++ & +++ & +++ \\
\hline Proportion of river and flooded area & & & +++ & ++ & +++ \\
\hline Proportion of lakes & & & n.s. & - & - \\
\hline Density of rivers and streams & & & ++ & n.s. & ++ \\
\hline \multicolumn{6}{|l|}{ Goodness of fit metrics } \\
\hline AIC & $676.6 \pm 10.6$ & $2172.6 \pm 35.2$ & $2131.6 \pm 27.1$ & $1765.9 \pm 18.2$ & $565.3 \pm 26.7$ \\
\hline AUC & $0.750 \pm 0.009$ & $0.808 \pm 0.004$ & $0.828 \pm 0.004$ & $0.792 \pm 0.005$ & $0.909 \pm 0.006$ \\
\hline Cohen's k & $0.242 \pm 0.003$ & $0.392 \pm 0.002$ & $0.434 \pm 0.015$ & $0.338 \pm 0.023$ & $0.629 \pm 0.022$ \\
\hline Pseudo $\mathrm{R}^{2}$ & $0.129 \pm 0.014$ & $0.215 \pm 0.013$ & $0.241 \pm 0.005$ & $0.185 \pm 0.013$ & $0.421 \pm 0.026$ \\
\hline
\end{tabular}

*The parameters of these models are provided in Table 2

Models 1 and 2 are those corresponding to the previously published studies, i.e. for the first period (July 3 - September 30, 2004) and the second (October 1, 2004 - April 1, 2005), respectively. Model 3 expands model 2 by including water-related variables. Models 4 and 5 include the presence of an outbreak in chickens and ducks, respectively, as the dependent variable. Results are presented as either not significant (n.s.) or significant at p-levels $<0.001(+++),<0.01(++)$ or $<0.05(+)$. Significance was evaluated as significance of change in log-likelihood predictor removal.

period showing a positive association with the presence of HPAI H5N1 at the sub-district level were the number of native chickens, the number of cocks, the human population and the mean crop intensity. During the second period, the predictors were the number of free-grazing ducks, the number of cocks, and the mean crop intensity. Model 3 was significantly improved by the addition of water-related variables, with an average area under the curve (AUC) increasing from 0.812 to 0.834 .

Fig. 1 presents the distribution of the two waterrelated variables that were found significant, i.e. the distribution of land covered by rivers and flooding and the density of rivers and streams at the sub-district level. The sign and significance of the other predictors remained similar to model 2 but without the water predictors.

The presence of HPAI H5N1 in chickens was most accurately predicted by the number of free-grazing ducks, the number of cocks, the mean crop intensity, the proportion of rivers and flooded land and the density of rivers and streams (model 4, Table 1 ). In the duck outbreaks models (model 5, Table 1), we found that the main predictors associated with HPAI H5N1 presence were the number of meat and layer duck, the number of free-grazing ducks, the number of cocks, the mean cropping intensity, the proportion of land covered by rivers and flooding and the density of rivers and streams. We also found a negative association with the number of native chickens.

Table 2 presents the parameters of models 4 and 5, i.e. the model of HPAI H5N1 chicken or duck outbreaks, respectively, with all predictors included. The change in log-likelihood upon removal of each variable was used as an indicator of the contribution of each variable to the model fit, and allowed a better contrast with respect to the differences between the two models. For outbreaks observed in chickens, the number of 
Table 2. Parameters of the autologistic chicken and duck regression models.

\begin{tabular}{|c|c|c|c|}
\hline Chicken outbreak model & Coefficient & ChLL* & Significance \\
\hline Constant & -2.95 & & \\
\hline Broiler and layer chicken & $-1.6110^{-7} \pm 4.7810^{-7}$ & 0.573 & $\mathrm{P}=0.449$ \\
\hline Native chicken & $-1.3010^{-6} \pm 6.0910^{-6}$ & 0.629 & $\mathrm{P}=0.428$ \\
\hline Meat-and-layer duck & $-3.4710^{-7} \pm 2.9410^{-6}$ & 0.257 & $P=0.612$ \\
\hline Free-grazing duck & $2.7610^{-5} \pm 7.9510^{-6}$ & 24.4 & $\mathrm{P}<0.001$ \\
\hline Cock & $1.2710^{-4} \pm 2.7710^{-5}$ & 57.1 & $\mathrm{P}<0.001$ \\
\hline Human population & $8.8710^{-7} \pm 6.7710^{-6}$ & 2.14 & $\mathrm{P}=0.144$ \\
\hline Mean crop intensity & $8.9410^{-1} \pm 6.4010^{-2}$ & 34.9 & $\mathrm{P}<0.001$ \\
\hline Proportion of river and flooded area & $1.90 \pm 0.39$ & 9.27 & $\mathrm{P}=0.002$ \\
\hline Density of rivers and streams & $241 \pm 90$ & 1.90 & $P=0.169$ \\
\hline Proportion of lakes & $-5.97 \pm 1.19$ & 4.48 & $\mathrm{P}=0.034$ \\
\hline Autoregressive term (Art) & $102 \pm 12$ & 64.1 & $\mathrm{P}<0.001$ \\
\hline \multicolumn{4}{|l|}{ Duck outbreak model } \\
\hline Constant & -4.08 & & \\
\hline Broiler and layer chicken & $-2.1710^{-6} \pm 1.8610^{-6}$ & 2.34 & $P=0.126$ \\
\hline Native chicken & $-3.3010^{-5} \pm 1.0210^{-5}$ & 4.08 & $\mathrm{P}=0.043$ \\
\hline Meat and layer duck & $3.3810^{-5} \pm 1.9410^{-5}$ & 11.3 & $\mathrm{P}<0.001$ \\
\hline Free-grazing duck & $4.9510^{-5} \pm 1.6110^{-5}$ & 37.1 & $\mathrm{P}<0.001$ \\
\hline Cocks & $1.0610^{-4} \pm 4.4410^{-5}$ & 11.3 & $\mathrm{P}<0.001$ \\
\hline Human population & $8.7910^{-6} \pm 9.4110^{-6}$ & 2.46 & $P=0.117$ \\
\hline Mean cropping intensity & $1.08 \pm 0.17$ & 17.5 & $\mathrm{P}<0.001$ \\
\hline Proportion of river and flooded area & $3.64 \pm 1.13$ & 12.6 & $\mathrm{P}<0.001$ \\
\hline Density of rivers and streams & $983 \pm 178$ & 8.93 & $P=0.003$ \\
\hline Proportion of lakes & $-13.2 \pm 2.7$ & 4.50 & $\mathrm{P}=0.034$ \\
\hline Autoregressive term (Art) & $145 \pm 22$ & 37.7 & $\mathrm{P}<0.001$ \\
\hline
\end{tabular}

* Change in log-likelihood upon removal

cocks was the predictor with the highest contribution to the model predictability. It was followed by the mean crop intensity, the number of free-grazing ducks, the density of rivers and streams and the proportion of land covered by rivers or flooding. In contrast, outbreaks in ducks were best predicted, by decreasing order of contribution to the model fit, by the number of free-grazing ducks, the number of meat-and-layer ducks, the density of rivers and streams, the mean crop intensity, the proportion of land covered by rivers or flooding and the number of cocks. The geographical distribution of the predictions made by these two models is presented in Fig. 3. The figure highlights that the risk of a chicken outbreak is predicted to be distributed over a much wider area than the risk of an outbreak in ducks that is merely restricted to the central plain with high duck populations.

\section{Discussion}

The geographical distribution of HPAI H5N1 epidemics has already been investigated in several studies that have specifically analysed the statistical relationship between presence data at the sub-district level and several variables, or risk factors. These studies have allowed quantifying the possible effect of those risk factors, and to map the geographical distribution of HPAI H5N1 presence risk. However, the role of water in the landscape has not been previously assessed because of a lack of high-resolution information on the distribution of flooded land at the time of the epidemic. The incorporation of predictors of the water distribution in the landscape improved the HPAI H5N1 model during of the main epidemic of 2004/2005 in Thailand. The improvement was mod- 

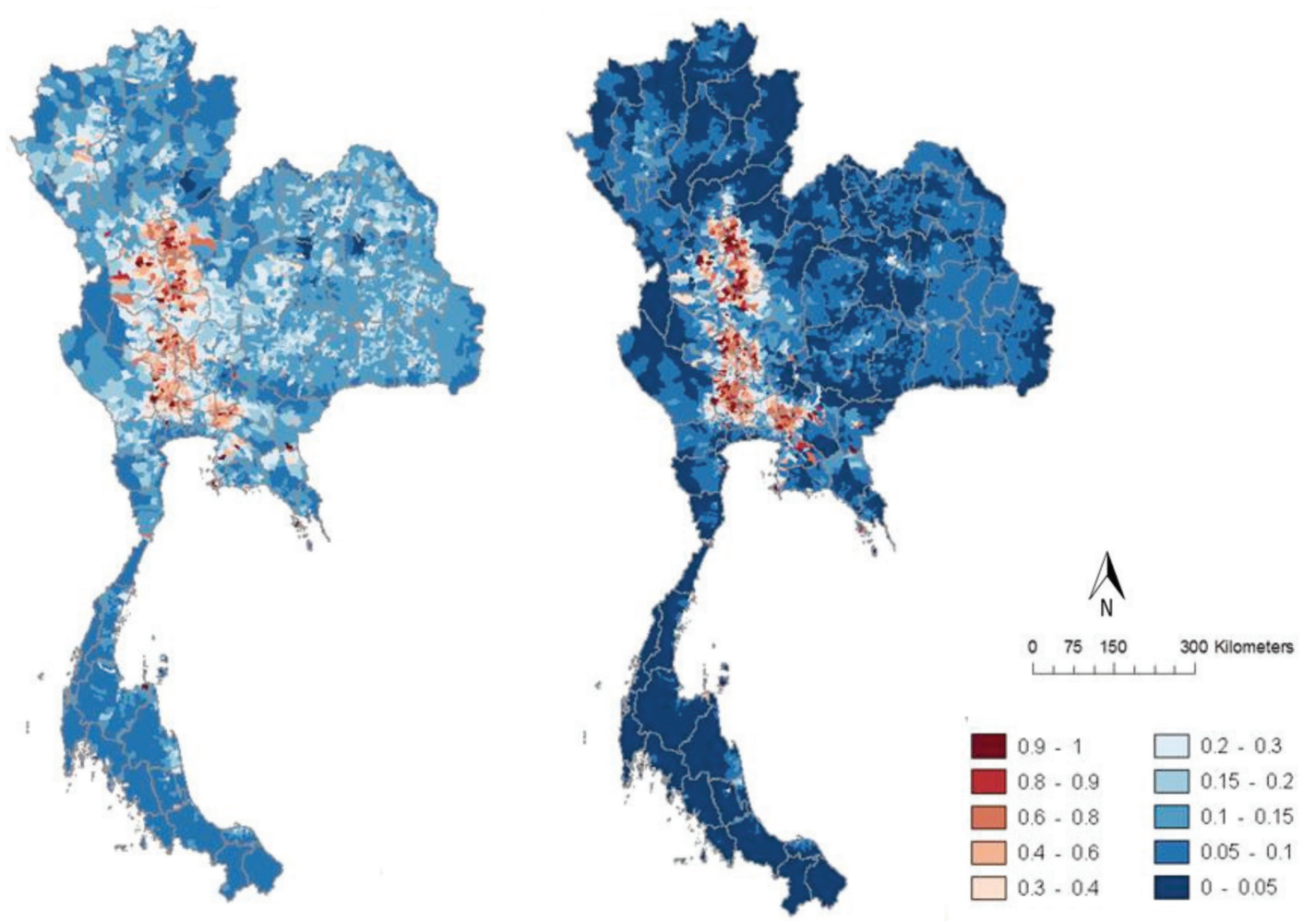

Fig. 3. Predicted HPAI H5N1 risk distribution based on chicken (left) and duck (right) outbreaks in Thailand in 2004/2005.

erate, because a large part of the spatial variability was already explained by previous models including host-related variables and other predictors. In fact, if one removes the crop intensity variable from model 3 , the variable describing the proportion of land covered by rivers and flooding becomes the third most important variable (just after the number of free-grazing ducks and the number of cocks). Water-related variables are apparently important in predicting both chicken and duck outbreaks, though the proportion of land covered by rivers and floods appeared slightly less important in predicting chicken than duck outbreaks (Table 2).

Out of the three indicators of water presence, two were found to contribute significantly to the model fit: the proportion of flooded land in each sub-district at the time of the epidemic, and the density of rivers and streams. Both variables are potentially important descriptors of domestic duck habitats, i.e. areas where they can actively forage for food. With the HPAI $\mathrm{H} 5 \mathrm{~N} 1$ virus being able to persist in water and tropical conditions (Horm et al., 2012), landscapes that combine both high densities of free-grazing ducks, a dense network of irrigation and river, and large, temporarily inundated land provide suitable conditions for waterborne transmission.
The two main water variables identified in this study are complementary. The spatial resolution of $30 \mathrm{~m}$ of the freely available Landsat images is not sufficient of detecting small streams, canals and rivers. In this case, the database of rivers and streams adds a level of detail that the remotely sensed data cannot provide. In contrast, these streams and rivers data, representing the potential water network, may not have been filled at the time of the epidemic and may therefore not be effectively used as domestic duck habitats or involved in HPAI H5N1 transmission. Furthermore, this database does not cover the large parts of land inundated by water. In this regard, medium-resolution satellite imagery adds a temporally explicit estimate of the actual presence of water in the field that the river and stream database cannot capture. Interestingly, although we had somehow anticipated that these two variables would replace the mean crop intensity in the model, the latter remained significant. This suggests that the mean crop intensity describes landscape features typically associated with HPAI H5N1, which was not captured by the datasets of rivers, streams or inundated water bodies tested here. Permanent water bodies such as dams were not found to correlate with HPAI H5N1 risk. These are mostly located in the highlands and constructed for hydroelectric and irrigation purposes and not associat- 
ed with the cropland directly. The irrigation networks, in contrast to the canals are dug in the central plain to carry floodwaters from the Chao Phraya River to the croplands. Similar results linking HPAI H5N1 risk to the presence or abundance of water were already found in Romania (Ward et al., 2008), People's Republic of China (Fang et al., 2008; Martin et al., 2011), and also in Thailand (Paul et al., 2011) where the presence of HPAI H5N1 at the farm level was found to be associated with the presence of a pond or canal around the farmhouse. This risk factor appears at a different scale in Thailand but also in very different agricultural and climatic conditions such as those encountered in People's Republic of China or Romania.

Along the water-related variables, a few other interesting results are provided by this study. First, cocks were found to be a much stronger risk factor than in previous studies. Cocks are frequently transported over long distances to arenas for fighting or training where transmission can easily occur. These activities may have enhanced the odds of transmission over relatively long distances between infected and susceptible hosts. Second, we observed a shift in the most important risk factor between period I and period II. During the first period, the main risk factors were the number of cocks and native chickens, while the number of free-grazing ducks was not found to be associated with the presence of HPAI H5N1 outbreaks. In the second period, however, the number of native chickens was no longer an important factor as the risk was of relatively much higher importance with respect to the free-grazing ducks and mean-crop intensity. This may be linked to their different roles during the two periods of the epidemics with a primary period with a relatively stable and low incidence, mainly associated with native chicken and cocks, and a second period with an epidemic flare-up associated with free-grazing ducks and cocks. Previous models had also identified human population as a significant risk factor (Gilbert et al., 2006), whereas we only found this factor to be significant during period I. However, this is not contradictory since previous studies pooled the epidemic data into a single dataset.

The water-related variable identified in this work call for landscape-scale studies, where the actual distribution of small canals, rivers, ponds, rice paddy fields and farms could be mapped and matched against farm-level data on HPAI H5N1 presence. This would provide more explicit hypotheses regarding the potential transmission through water, which could be tested by targeting the space-time distribution of HPAI $\mathrm{H} 5 \mathrm{~N} 1$ cases in relation to the distribution of rice harvest and the network of irrigation canals.

\section{Acknowledgements}

This study was supported by grants from the U.S. National Institutes of Health Fogarty International Center (R01TW007869), and NASA Earth Science Applications - Public Health Program (NNX11AF66G). We are grateful to the staff of the Thai Department of Livestock Development, Ministry of Agriculture and Cooperatives who helped control the HPAI epidemic in Thailand.

\section{References}

Adhikari D, Chettri A, Barik SK, 2009. Modelling the ecology and distribution of highly pathogenic avian influenza (H5N1) in the Indian subcontinent. Curr Sci India 97, 73-78.

Ahmed SSU, Ersbøll AK, Biswas PK, Christensen JP, Hannan ASMA, Toft N, 2012. Ecological determinants of highly pathogenic avian influenza (H5N1) outbreaks in Bangladesh. PLoS One 7, e33938.

Augustin NH, Mugglestone MA, Buckland ST, 1996. An autologistic model for the spatial distribution of wildlife. J Appl Ecol 33, 339-347.

Brown JD, Goekjian G, Poulson R, Valeika S, Stallknecht DE, 2009. Avian influenza virus in water: infectivity is dependent on $\mathrm{pH}$, salinity and temperature. Vet Microbiol 136, 20-26.

Domanska-Blicharz K, Minta Z, Smietanka K, Marché S, van den Berg T, 2010. H5N1 high pathogenicity avian influenza virus survival in different types of water. Avian Dis 54, 734-737.

Exelis VIS, 2010. ENVI 5.0, Exelis visual information solutions. Boulder, Colorado.

Fang LQ, de Vlas SJ, Liang S, Looman CW, Gong P, Xu B, Yan L, Yang H, Richardus JH, Cao WC, 2008. Environmental factors contributing to the spread of $\mathrm{H} 5 \mathrm{~N} 1$ avian influenza in mainland China. PLoS One 3, e2268.

Gilbert M, Chaitaweesub P, Parakarnawongsa T, Premashthira S, Tiensin T, Kalpravidh W, Wagner H, Slingenbergh J, 2006. Free-grazing ducks and highly pathogenic avian influenza, Thailand. Emerg Infect Dis 12, 227-234.

Gilbert M, Newman SH, Takekawa JY, Loth L, Biradar C, Prosser DJ, Balachandran S, Subba Rao MV, Mundkur T, Yan B, Xing Z, Hou Y, Batbayar N, Natsagdorj T, Hogerwerf L, Slingenbergh J, Xiao X, 2011. Flying over an infected landscape: distribution of highly pathogenic avian influenza H5N1 risk in South Asia and satellite tracking of wild waterfowl. EcoHealth 7, 448-458.

Gilbert M, Pfeiffer DU, 2012. Risk factor modelling of the spatiotemporal patterns of highly pathogenic avian influenza (HPAIV) H5N1: a review. Spat Spatiotemporal Epidemiol 3, 173-183.

Gilbert M, Xiao X, Pfeiffer DU, Epprecht M, Boles S, Czarnecki C, Chaitaweesub P, Kalpravidh W, Minh PQ, Otte MJ, Martin V, Slingenbergh J, 2008. Mapping H5N1 highly pathogenic avian influenza risk in Southeast Asia. Proc Natl Acad Sci USA 
105, 4769-4774.

Gilbert M, Xiao XM, Chaitaweesub P, Kalpravidh W, Premashthira S, Boles S, Slingenbergh J, 2007. Avian influen$\mathrm{za}$, domestic ducks and rice agriculture in Thailand. Agr Ecosyst Environ 119, 409-415.

Horm VS, Gutiérrez RA, Nicholls JM, Buchy P, 2012. Highly pathogenic influenza A (H5N1) virus survival in complex artificial aquatic biotopes. PLoS One 7, e34160.

Loth L, Gilbert M, Osmani MG, Kalam MA, Xiao X, 2010. Risk factors and clusters of highly pathogenic avian influenza H5N1 in Bangladesh. Prev Vet Med 96, 104-113.

Loth L, Gilbert M, Wu J, Czarnecki C, Hidayat M, Xiao X, 2011. Identifying risk factors of highly pathogenic avian influenza (H5N1 subtype) in Indonesia. Prev Vet Med 102, 50-58.

Marquetoux N, Paul M, Wongnarkpet S, Poolkhet C, Thanapongtharm W, Roger F, Ducrot C, Chalvet-Monfray K, 2012. Estimating spatial and temporal variations of the reproduction number for highly pathogenic avian influenza H5N1 epidemic in Thailand. Prev Vet Med 106, 143-151.

Martin V, Pfeiffer DU, Zhou X, Xiao X, Prosser DJ, Guo F, Gilbert M, 2011. Spatial distribution and risk factors of highly pathogenic avian influenza (HPAI) H5N1 in China. PLoS Pathog 7, e1001308.

OIE (World Organization for Animal Health), 2011. World Animal Health Information Database (WAHID), 2011. Available at: http://www.oie.int/wahis/public.php?page=home (accessed on ...).

Paul M, Tavornpanich S, Abrial D, Gasqui P, Charras-Garrido M, Thanapongtharm W, Xiao X, Gilbert M, Roger F, Ducrot C, 2010. Anthropogenic factors and the risk of highly pathogenic avian influenza H5N1: prospects from a spatial-based model. Vet Res 41, 28.

Paul M, Wongnarkpet S, Gasqui P, Poolkhet C, Thongratsakul S, Ducrot C, Roger F, 2011. Risk factors for highly pathogenic avian influenza (HPAI) H5N1 infection in backyard chicken farms, Thailand. Acta Trop 118, 209-216.

Pfeiffer DU, Minh PQ, Martin V, Epprecht M, Otte MJ, 2007. An analysis of the spatial and temporal patterns of highly pathogenic avian influenza occurrence in Vietnam using national surveillance data. Vet J 174, 302-309.

Scaramuzza P, Micijevic E, Chander G, 2004. SLC gap-filling prodcuts, Phase 1 methodology. Available from: http://land-
sat.usgs.gov/documents/SLC_Gap_Fill_Methodology.pdf (accessed on March 2012).

Songserm T, Sae-Heng N, Jam-on R, Witoonsatient K, Meemak $\mathrm{N}, 2005$. Clinical, gross-histopathologic and immunohistochemical finding of grazing ducks affected with HPAI H5N1 in Thailand. In: Abstracts of the OIE/FAO International Conference on avian influenza. Paris, April 6-7, 2005.

Souris M, Gonzalez J-P, Shanmugasundaram J, Corvest V, Kittayapong P, 2010. Retrospective space-time analysis of H5N1 Avian Influenza emergence in Thailand. Int J Health Geogr 9, 11.

Tiensin T, Ahmed SSU, Rojanasthien S, Songserm T, Ratanakorn P, Chaichoun K, Kalpravidh W, Wongkasemjit S, Patchimasiri T, Chanachai K, 2009. Ecologic risk factor investigation of clusters of avian influenza A (H5N1) virus infection in Thailand. J Infect Dis 199, 1735-1743.

Tiensin T, Chaitaweesub P, Songserm T, Chaisingh A, Hoonsuwan W, Buranathai C, Parakamawongsa T, Premashthira S, Amonsin A, Gilbert M, Nielen M, Stegeman A, 2005. Highly pathogenic avian influenza H5N1, Thailand, 2004. Emerg Infect Dis 11, 1664-1672.

Tiensin T, Nielen M, Songserm T, Kalpravidh W, Chaitaweesub P, Amonsin A, Chotiprasatintara S, Chaisingh A, Damrongwatanapokin S, Wongkasemjit S, 2007. Geographic and temporal distribution of highly pathogenic avian influenza A virus (H5N1) in Thailand, 2004-2005: an overview. Avian Dis 51, 182-188.

Tran A, Goutard F, Chamaille L, Baghdadi N, Lo Seen D, 2010. Remote sensing and avian influenza: a review of image processing methods for extracting key variables affecting avian influenza virus survival in water from Earth observation satellites. Int J Appl Earth Obs 12, 1-8.

Tou JT, Gonzalez RC, 1974. Pattern recognition principles. Addison-Wesley Publishing Company, Reading, Massachusetts. Walker P, Cauchemez S, Hartemink N, Tiensin T, Ghani AC, 2012. Outbreaks of H5N1 in poultry in Thailand: the relative role of poultry production types in sustaining transmission and the impact of active surveillance in control. J R Soc Interface 9, 1836-1845.

Ward MP, Maftei D, Apostu C, Suru A, 2008. Environmental and anthropogenic risk factors for highly pathogenic avian influenza subtype H5N1 outbreaks in Romania, 2005-2006. Vet Res Commun 32, 627-634. 